\title{
Effect of amplitude and duration of impulsive pressure on endothelial permeability in in vitro fluid percussion trauma
}

\author{
Hiromichi Nakadate ${ }^{1 *}$, Koji Inuzuka$^{1}$, Suguru Akanuma ${ }^{1}$, Akira Kakuta $^{2}$ and Shigeru Aomura ${ }^{1}$
}

\author{
* Correspondence: \\ nakadate@tmu.ac.jp \\ ${ }^{1}$ Graduate School of System Design, \\ Tokyo Metropolitan University, \\ Tokyo, Japan \\ Full list of author information is \\ available at the end of the article
}

\begin{abstract}
Background: Intracranial pressure changes during head impact cause brain injuries such as vasogenic edema and cerebral contusion. However, the influence of impulsive pressure on endothelial function has not yet been fully studied in vitro. In this study, we developed a pressure loading device that produced positive and negative pressures by modifying an in vitro fluid percussion model and examined the effects of the amplitude and duration of the pressures on endothelial permeability.

Methods: Human umbilical vein endothelial cells were subjected to three types of positive pressure (average amplitude/average duration of $352 \mathrm{kPa} / 23 \mathrm{~ms}, 73 \mathrm{kPa} / 27 \mathrm{~ms}$, and $70 \mathrm{kPa} / 44 \mathrm{~ms})$ and three types of negative pressure $(-72 \mathrm{kPa} / 41 \mathrm{~ms},-67 \mathrm{kPa} /$ $104 \mathrm{~ms}$, and $-91 \mathrm{kPa} / 108 \mathrm{~ms}$ ), and the transendothelial electrical resistance (TEER) was measured between 15 min and $24 \mathrm{~h}$ after pressure loading for quantifying the formation of an integral monolayer of endothelial cells. After loading, vascular endothelial- (VE-) cadherin, an endothelium-specific cell-cell adhesion molecule involved in endothelial barrier function, was stained and observed using fluorescence microscopy.

Results: The pressure loading device could produce positive pressure pulses with amplitudes of 53-1348 kPa and durations of 9-29.1 ms and negative pressure pulses with amplitudes of -52--93 kPa and durations of 42.9-179.5 ms. The impulsive pressure reduced the TEER associated with the change in VE-cadherin localization. Additionally, TEER decreased considerably at $15 \mathrm{~min}$ and $6 \mathrm{~h}$ post-loading, with these changes being significant in positive pressure with larger amplitude and shorter duration and in all types of negative pressures compared to pre-loading.
\end{abstract}

Conclusions: The changes in intracranial pressure during head impact impair endothelial barrier function by the disruption of the integrity of endothelial cell-cell junctions, and the degree of increase in endothelial permeability depends on the amplitude, duration, and direction (compressive and tensile) of the impulsive pressure.

Keywords: Head impact, Impulsive pressure, Fluid percussion, Positive pressure, Negative pressure, Pressure amplitude, Pressure duration, Endothelial permeability, Transendothelial electrical resistance, Vascular endothelial cadherin

\section{Background}

Head impact causes a dynamic mechanical response such as a pressure gradient within the brain and shear deformation of the brain tissue, resulting in brain injury [1,2]. Animal studies of head impact have shown that the transient increase in intracranial pressure causes brain haemorrhage and cerebral concussion $[3,4]$. Typically, the pressure generated

(c) 2014 Nakadate et al.; licensee BioMed Central Ltd. This is an Open Access article distributed under the terms of the Creative Commons Attribution License (http://creativecommons.org/licenses/by/2.0), which permits unrestricted use, distribution, and reproduction in any medium, provided the original work is properly credited. The Creative Commons Public Domain Dedication waiver (http://creativecommons.org/publicdomain/zero/1.0/) applies to the data made available in this article, unless otherwise stated. 
at the impact site (coup pressure) was positive and that generated on the side opposite to the impact site (contrecoup pressure) was negative in experiments using human cadavers [5-7]. We have demonstrated that positive and negative pressure fluctuations were generated at the impact site and the opposite side through a finite element simulation of nine real-world accident cases involving fatal cerebral contusion [8]. To date, various in vitro models have been developed for understanding the mechanical stimuli during an impact event and the subsequent responses of tissue and cells [9]. A fluid percussion model produced a transient pressure pulse during head impact more accurately [10,11]; however, the difference between positive and negative pressures has not been examined in in vitro models of trauma. Studies of experimental animals using a fluid percussion injury model and controlled cortical impact model have shown that cerebral vascular dysfunction such as morphologic damage to endothelial cells and increased permeability of blood-brain barrier (BBB) forms a physical barrier to filter blood-borne substances between the blood and the brain parenchyma [12]; however, the effects of pressure on cultured cells have been poorly studied relative to the effects of deformation, and few studies have focused on the endothelial cells of brain microvessels $[11,13,14]$, which define one component of BBB, compared to central nervous system (CNS) cells such as neurons, astrocytes, and glial cells. In addition, the direct influence of impulsive pressure during head impact on the structure and function of endothelial cells in vitro has not yet been fully studied.

This study aims to better understand the contribution of brain mechanical responses to cerebral vascular injury resulting in vasogenic edema and cerebral contusion. Previously, we have demonstrated that transient positive and negative pressures increased the endothelial permeability to FITC-dextran [15]. In the present study, we examined the effects of the amplitude and duration of positive and negative pressures on the capillary-like structure and endothelial permeability using a pressure loading device developed by modifying an in vitro fluid percussion model.

\section{Methods}

\section{Endothelial cell culture}

Human umbilical vein endothelial cells (HUVEC) purchased from Lonza (Walkersville, MD, USA) were cultured in Endothelial Basal Medium-2 (EBM-2) supplemented with an EGM-2 SingleQuots containing recombinant human epidermal growth factor (rhEGF), heparin, hydrocortisone, recombinant human fibroblast growth factor-basic (rhFGF-B), ascorbic acid, recombinant human vascular endothelial growth factor (VEGF), recombinant long $r$ insulin-like growth factor-1 ( $\mathrm{R}^{3}$-IGF-1), gentamicin sulphate amphotericin-B (GA-1000), and foetal bovine serum (FBS) under conditions of $5 \% \mathrm{CO}_{2}$ and $100 \%$ humidity at $37^{\circ} \mathrm{C}$. HUVEC from passages 3-5 were seeded at $50 \times 10^{4}$ cells on BD Matrigel matrix-coated $35-\mathrm{mm}$ culture dishes (Asahi Technoglass, Tokyo, Japan) and were grown to tube formations within $24 \mathrm{~h}$ for evaluating the capillary-like structure. HUVEC from passages 3-5 were seeded at $4.4 \times 10^{5}$ cells/well into cell culture inserts (6-well format, 0.4- $\mu$ m pore size, BD, Franklin Lakes, NJ, USA) and were grown to confluent monolayers within $24 \mathrm{~h}$ for evaluating the endothelial cell function.

\section{Pressure loading device}

We employed the percussion of a pendulum, as described by Shepard et al. [10], on a pressure loading device consisting of a cylinder, a piston, a pendulum with a weight of 1 
or $2 \mathrm{~kg}$, a pressure chamber, and a pressure transducer (Figure 1A and B). The angle of the pendulum, having a radius of $500 \mathrm{~mm}$ and attached to an aluminium frame, can be adjusted from $0^{\circ}$ to $90^{\circ}$. Figure $1 \mathrm{C}$ shows a cross-sectional diagram of the cylinder, piston, and pressure chamber. The pressure chamber is divided by a $0.5-\mathrm{mm}$ silicone membrane. The upper stainless-steel compartment is filled with water and is connected to the cylinder. The lower polycarbonate compartment including the culture dish or the culture insert is filled with culture medium and connected to a pressure transducer with a working range of -98.07-2000 kPa (PGM-20KH, Kyowa, Tokyo). We designed and produced the cylinder and piston unit using brass and stainless-steel so as to produce both positive and negative pressures. The cylinder had a length and diameter of $100 \mathrm{~mm}$ and $35 \mathrm{~mm}$, respectively. The piston's corresponding dimensions were $410 \mathrm{~mm}$ and $16 \mathrm{~mm}$. Two striking heads were attached at either end of the piston, and an O-ring was attached in the middle of the piston. One compartment, which is separated from the cylinder by the O-ring and is

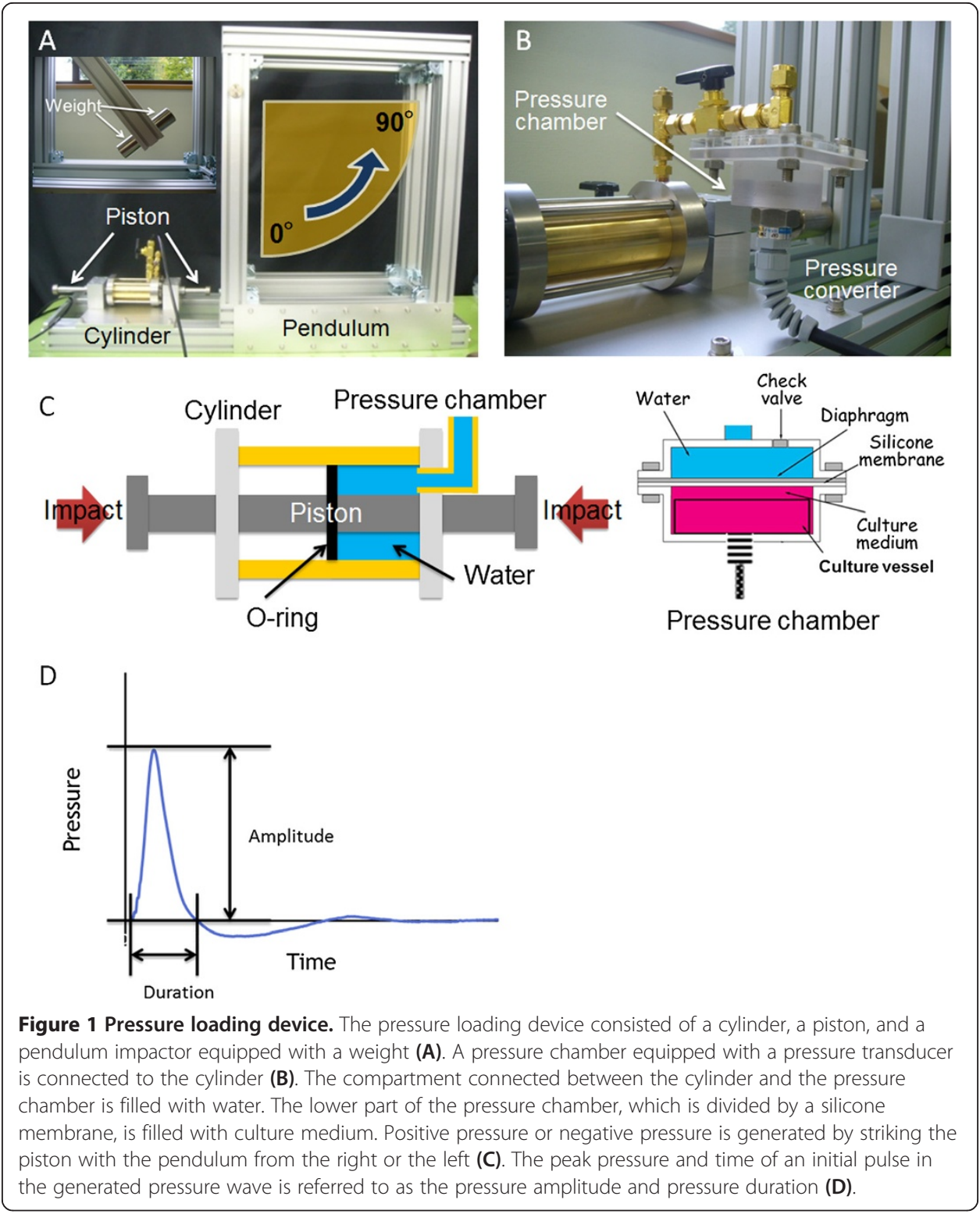


connected to the pressure chamber, is filled with water; therefore, the change in the striking direction made it possible to switch positive and negative pressure. The impulsive pressure shown in Figure 1D is generated by striking the piston with the weight attached to the pendulum. In the case of impact from the left, the water in the cylinder is compressed and positive pressure is generated; this pressure propagates to the pressure chamber. In the case of impact from the right, the water in the cylinder is stretched and negative pressure is generated.

\section{Measurement of transendothelial electrical resistance (TEER)}

Following impulsive pressure loading, the cell culture insert was transferred from the pressure chamber into an EndOhm chamber (World Precision Instruments, Sarasota, FL, USA), and the electrical resistance across HUVEC monolayers was measured using an $\mathrm{EVOM}^{2}$ resistance meter (World Precision Instruments). The electrical resistance of blank inserts was subtracted from the results. In some experiments, HUVEC were incubated with a culture medium containing ethyleneglycotetraacetic acid (EGTA), a calcium chelator, with a final concentration of $2.5 \mathrm{mM}$ at $37^{\circ} \mathrm{C}$ for $20 \mathrm{~min}$. Fresh medium was then added after EGTA was removed, and the electrical resistance was measured without impulsive pressure loading. Lower TEER disrupts the endothelial integrity and in turn, the intercellular gap formation. Extracellular $\mathrm{Ca}^{2+}$ depletion by EGTA is followed by the loss of cell-cell adhesion proteins and induced intercellular gap formation [16].

\section{Immunofluorescence staining}

After impulsive pressure loading and incubation with EGTA, HUVEC were rinsed with Hanks' Balanced Salt Solution (HBSS) without $\mathrm{Ca}^{2+}$ and $\mathrm{Mg}^{2+}$ and fixed with $4 \%$ paraformaldehyde in phosphate buffered saline (PBS) for $10 \mathrm{~min}$ at $4^{\circ} \mathrm{C}$; vascular endothelial- (VE-) cadherin, an endothelium-specific cell-cell adhesion molecule involved in the endothelial barrier function [17], was stained with $1 \mu \mathrm{g} / \mathrm{mL}$ rabbit anti-human VE-cadherin polyclonal antibody (BMS158, Bender MedSystems, CA, USA) as the primary antibody overnight at room temperature and with goat anti-rabbit IgG fluorescein conjugate (sc-2021, Santa Cruz Biotechnology, TX, USA) at a dilution of 1:400 as the secondary antibody overnight at room temperature. After HUVEC were washed with PBS, fluorescence images were observed using a fluorescence microscope (IX71, Olympus, Japan) equipped with a cooled CCD camera (Penguin 600CL, Pixera, Japan).

\section{Statistical analysis}

The amplitude and duration of pressure pulses are expressed as the mean \pm deviation (SD) of 3 independent experiments. The density of capillary-like network and TEER are expressed as the mean \pm standard error of the mean (SEM) of 3-6 independent experiments. The means were compared by Steel's multiple comparison test. A $p$ value of less than 0.05 was considered significant.

\section{Results}

Outputs of pressure loading device

The amplitude and duration of the generated pressure were reproducible results and were controlled by the incidence angle of the pendulum and the magnitude of the 
weight. The amplitude of positive and negative pressures increased with the angle and weight (Figure 2A and $\mathrm{C}$ ); however, the change in negative pressure was smaller than that in positive pressure. The duration of positive pressure decreased with increasing angle and weight (Figure 2B), whereas that of negative pressure increased with increasing angle and weight (Figure 2D); the change in negative pressure was larger than that in positive pressure. The amplitude and duration of the positive pressure were 53-1348 $\mathrm{kPa}$ and 9-29.1 ms, respectively (Figure 3A). The amplitude and duration of the negative pressure were $-52--93 \mathrm{kPa}$ and $42.9-179.5 \mathrm{~ms}$, respectively (Figure 3B).

\section{Disruption of capillary-like structure}

The changes in the capillary-like network formed by endothelial cells were observed using an inverted microscope before loading and at 1, 3, 6, and $24 \mathrm{~h}$ after loading of the impulsive pressure with amplitude of $-90-1200 \mathrm{kPa}$. The capillary-like structure was broken down after $1 \mathrm{~h}$ following impulsive pressure, and the capillary network gradually disappeared until $24 \mathrm{~h}$ after loading (Figure 4). The disappearance of the capillary network was not observed at a pressure amplitude of $350 \mathrm{kPa}$ or less (data not shown). Therefore, a pressure amplitude up to $350 \mathrm{kPa}$ was employed to evaluate the endothelial cell function, which serves as a measurement of TEER.

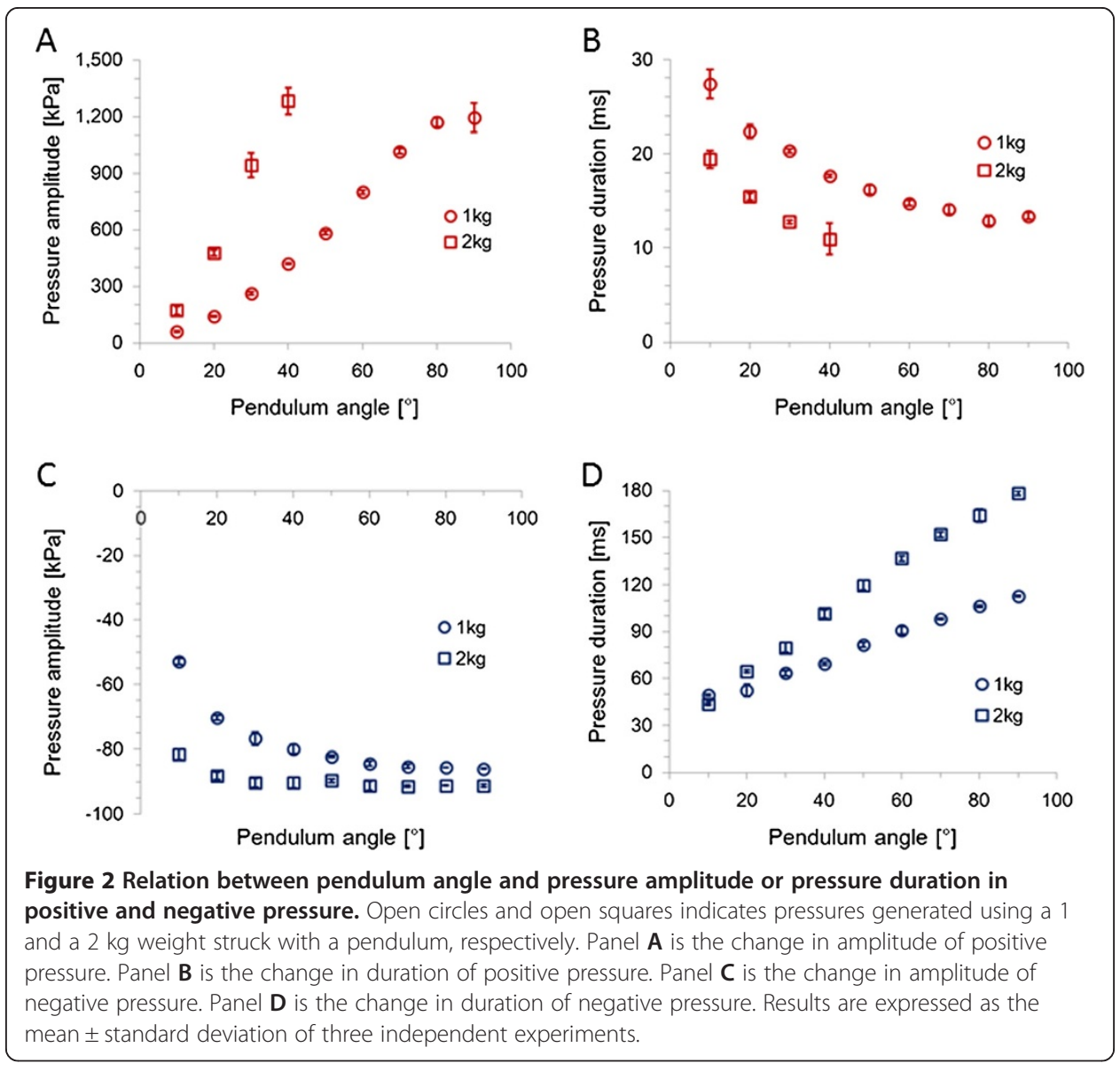



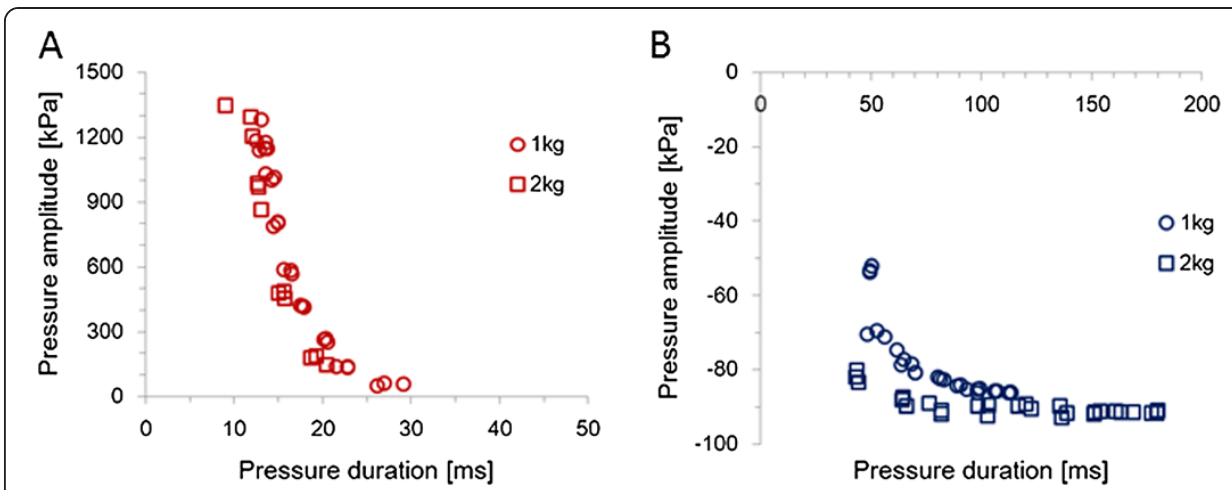

Figure 3 Combination of amplitude and duration of positive pressure and negative pressure. Open circles and open squares indicate pressures generated using a 1 and a $2 \mathrm{~kg}$ weight struck with a pendulum, respectively. The amplitudes are 53-1348 kPa and the durations are 9-29.1 ms in positive pressure (A). The amplitudes are $-52--93 \mathrm{kPa}$ and the durations are 42.9-179.5 ms in negative pressure (B)

\section{Decrease in TEER associated with changes in VE-cadherin localization}

HUVEC were subjected to six types of impulsive pressure, and the changes in TEER were measured before loading and at $15 \mathrm{~min}, 1 \mathrm{~h}, 3 \mathrm{~h}, 6 \mathrm{~h}$, and $24 \mathrm{~h}$ after loading (Figure 5). The representative waveforms and amplitudes and durations of the applied pressure pulses are shown in Figure 6 and Table 1, respectively. The TEER after loading of pressure pulse A with an average amplitude of $352 \mathrm{kPa}$ and average duration of $23 \mathrm{~ms}$ significantly decreased at all time points compared to the TEER of pre-loading, and it reached $\sim 85 \%$ at $15 \mathrm{~min}$ and $6 \mathrm{~h}$ after loading. The TEER after loading of pressure pulse B with an average amplitude of $73 \mathrm{kPa}$ and average duration of $27 \mathrm{~ms}$ significantly decreased after $3 \mathrm{~h}$ postloading compared to the TEER of pre-loading, and it reached $~ 90 \%$ at $6 \mathrm{~h}$ after loading. The TEER after loading of pressure pulse $\mathrm{C}$ with an average amplitude of $70 \mathrm{kPa}$ and average duration of $44 \mathrm{~ms}$ did not change significantly at all time points compared to the TEER of pre-loading. The TEER after loading of pressure pulse $\mathrm{D}$ with an average amplitude of $-72 \mathrm{kPa}$ and average duration of $41 \mathrm{~ms}$ significantly decreased except at $3 \mathrm{~h}$ postloading compared to the TEER of pre-loading, and it reached $90 \%$ at $15 \mathrm{~min}$ and $6 \mathrm{~h}$ after loading. The TEER after loading of pressure pulse $\mathrm{E}$ with an average amplitude of $-67 \mathrm{kPa}$ and average duration of $104 \mathrm{~ms}$ significantly decreased to approximately $90 \%$ at $15 \mathrm{~min}$ and $6 \mathrm{~h}$ after loading compared to the TEER of pre-loading. The TEER after loading of pressure pulse $\mathrm{F}$ with an average amplitude of $-91 \mathrm{kPa}$ and average duration of $108 \mathrm{~ms}$ significantly decreased to approximately $85 \%$ at $15 \mathrm{~min}$ and at $6 \mathrm{~h}$ after loading compared to the TEER of pre-loading. On the other hands, the TEER after exposure to EGTA largely decreased to approximately $15 \%$ at $15 \mathrm{~min}$ and then gradually recovered to approximately $50 \%$ at $24 \mathrm{~h}$ after loading. Additionally, VE-cadherin localization after loading six types of impulsive pressure and after exposure to EGTA was observed using a fluorescence microscope. VE-cadherin was localized along the cell-cell contacts continuously in the static culture (Figure 7A) and throughout the cells after EGTA incubation (Figure 7B). In contrast, VE-cadherin was observed intermittently along the cell-cell contacts and weakly in the cytoplasm after the loading of pressure pulses A and F, which induced the largest decrease in the TEER of six types of impulsive pressure (Figure 7C and D). Changes were rarely observed in VE-cadherin localization in endothelial cells subjected to pressure pulses except A and F, shown in Table 1. 

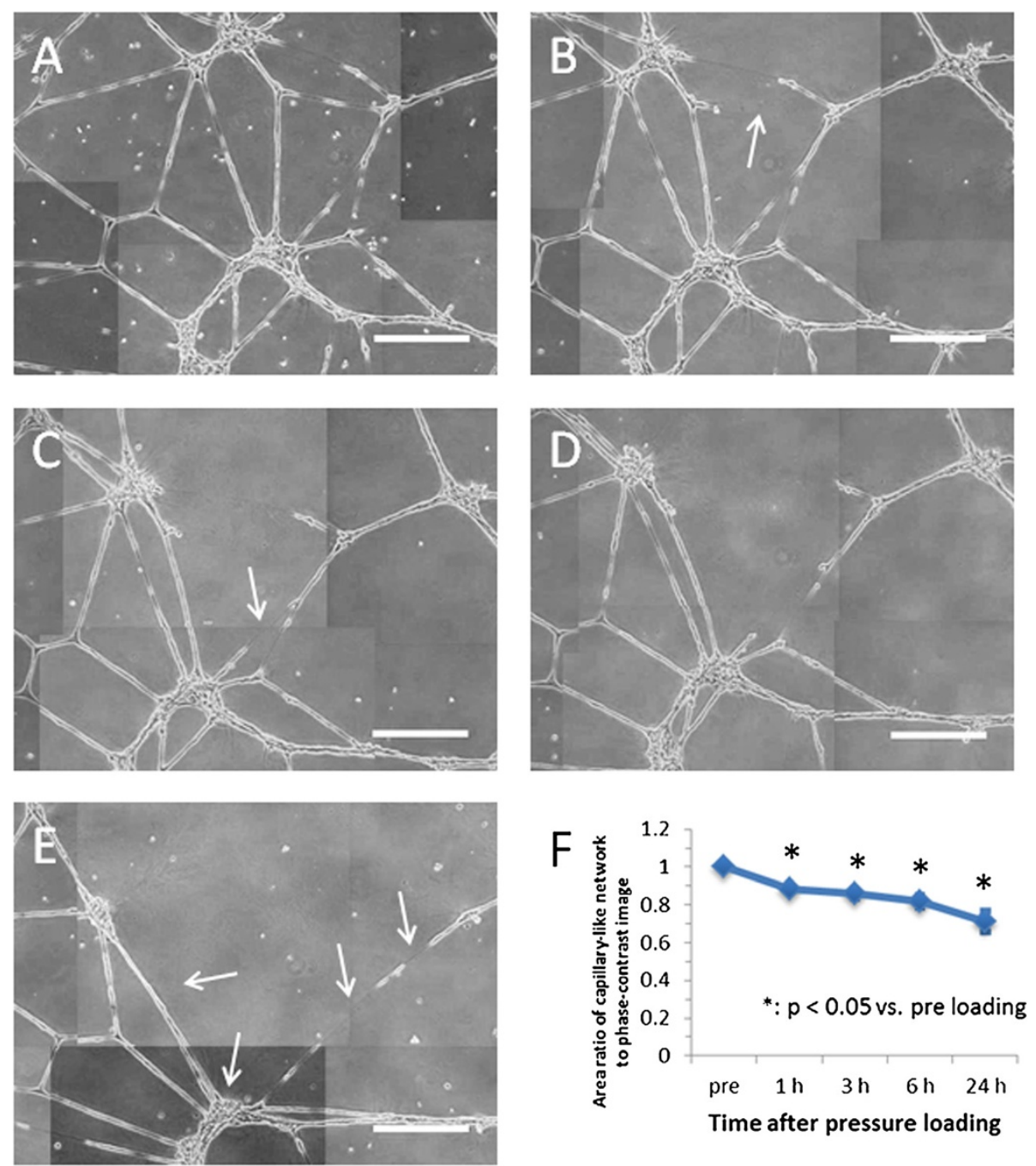

Figure 4 Phase-contrast images and density of capillary-like network formed by endothelial cells after loading of impulsive pressure. Endothelial tube formations were observed before loading (A) and at $1 \mathrm{~h}$ (B), $3 \mathrm{~h}$ (C), $6 \mathrm{~h}$ (D), and $24 \mathrm{~h}$ (E) after loading of impulsive pressure with amplitude of $1 \mathrm{MPa}$. Arrows indicate the disruption of the capillary-like structure. Scale bar is $400 \mu \mathrm{m}$. The area ratio of the capillary-like network to phase-contrast images was calculated time-dependently (F).

\section{Discussion}

The positive pressure in this study was comparable to that of other fluid percussion models and cadaver experiments, and the positive pressure waveform included a small negative pressure. For example, a negative pressure with a peak amplitude of $-25 \mathrm{kPa}$ followed a positive pressure with a peak amplitude of $350 \mathrm{kPa}$ (pressure pulse A shown in Figure 6). The secondary component of the negative pressure in the positive pressure waveform could not be suppressed in our pressure loading device; however, the complex waveforms of pressure fluctuation were measured in cadaver experiments [7]. Therefore, it would be necessary to control the pressure fluctuation generated by this device and to investigate the effect of secondary or multiple pressure components. The negative pressure, too, was comparable in terms of amplitude, but the duration was much longer. The pendulum impactor employed by Shepard et al. [10] generated a transient pressure pulse with an amplitude of $122-578 \mathrm{kPa}$ and duration of $20-30 \mathrm{~ms}$. 


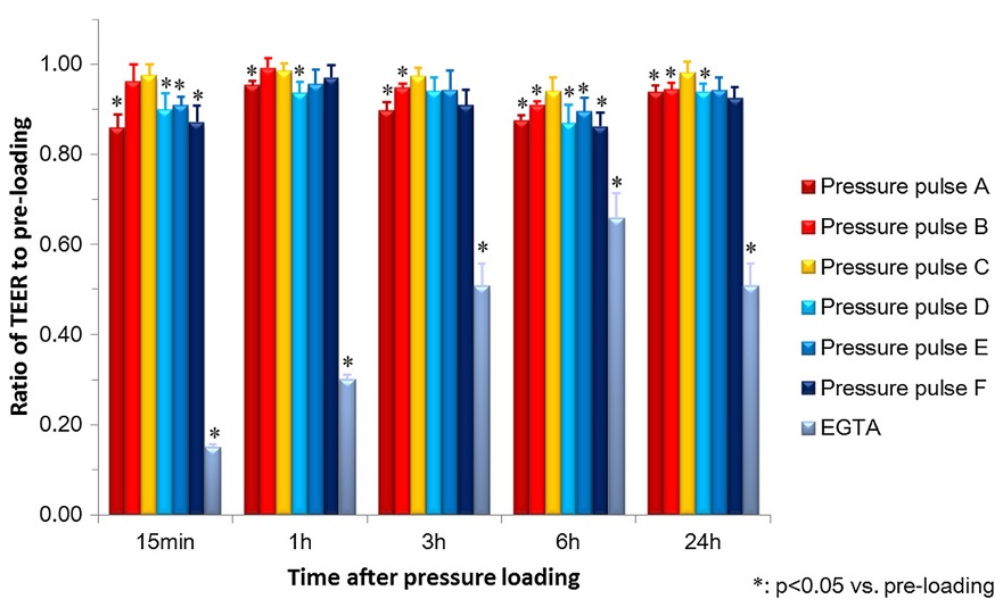

Figure $\mathbf{5}$ Change in transendothelial electrical resistance (TEER) after loading of impulsive pressure. The TEER before loading of impulsive pressure is 1.0. The * symbol represents a statistically significant difference $(p<0.05)$ versus pre-loading TEER at each condition using Steel's multiple comparison test. Results are expressed as the mean \pm standard error of 3-6 independent experiments.

The weight-dropping impactor employed by Orfeo et al. [11] generated a transient pressure pulse with an amplitude of $122-1013 \mathrm{kPa}$ and duration of 2-5 ms. Hardy et al. [7] reported that a positive pressure with an average peak amplitude of $51.0 \pm 32.1 \mathrm{kPa}$ and average duration of $20.4 \pm 20.4 \mathrm{~ms}$ and negative pressure with an average peak amplitude of $-55.3 \pm 36.7 \mathrm{kPa}$ and average duration of $4.7 \pm 2.5 \mathrm{~ms}$ were measured at the coup and contrecoup locations in 31 impacts using 7 human cadaver head specimens. In our pressure loading device, the extended duration of negative pressure correlated with the mechanical energy from the pendulum (Figure 2D). The duration of negative pressure increased because mechanical energy was not used to increase the peak amplitude but to extend the duration, because hydrostatic fluid pressure in the cylinder was not below $-100 \mathrm{kPa}$ even when the compressive stress of the piston, i.e. mechanical energy from the pendulum, increases with the angle and weight, unlike the positive pressure. Therefore, a piston with smaller energy could be used; however, it would be

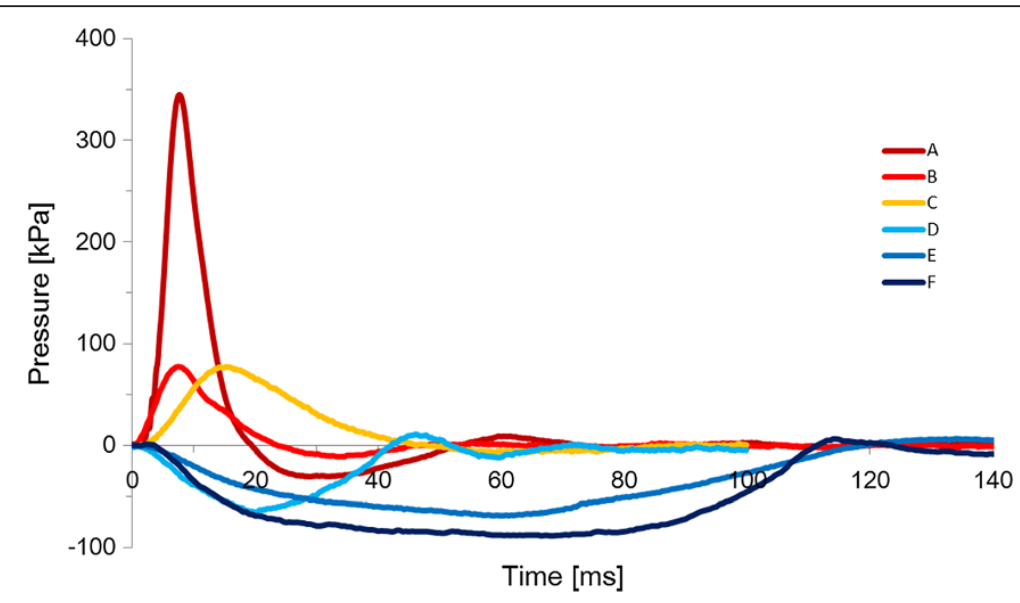

Figure 6 Representative waveform of pressure pulses applied to endothelial cells. A pressure pulse with a maximum pressure and duration of $350 \mathrm{kPa}$ and $20 \mathrm{~ms}$ (A), $70 \mathrm{kPa}$ and $20 \mathrm{~ms}$ (B), $70 \mathrm{kPa}$ and $40 \mathrm{~ms}$ (C), $-70 \mathrm{kPa}$ and $40 \mathrm{~ms}$ (D), $-70 \mathrm{kPa}$ and $100 \mathrm{~ms}(\mathbf{E})$, and $-90 \mathrm{kPa}$ and $100 \mathrm{~ms}$ (F), respectively. 
Table 1 Amplitude and duration of pressure pulses applied to endothelial cells

\begin{tabular}{ccc}
\hline Pressure pulse & Amplitude [kPa] & Duration [ms] \\
\hline A & $352 \pm 11$ & $23 \pm 2$ \\
B & $73 \pm 6$ & $27 \pm 1$ \\
C & $70 \pm 7$ & $44 \pm 0$ \\
D & $-72 \pm 7$ & $41 \pm 1$ \\
E & $-67 \pm 1$ & $104 \pm 4$ \\
F & $-91 \pm 3$ & $108 \pm 4$ \\
\hline
\end{tabular}

difficult to produce a negative pressure with a shorter duration equivalent to a realworld head impact.

This study demonstrated that impulsive pressure correlated with the disruption of capillary-like structures over time after impact. Recently, some studies have suggested that delayed and progressive haemorrhage during the first several hours after head impact are attributed to molecular events initiated at the time of impact, which lead to later structural failure of microvessels [18]. Simard et al. showed that necrotic death of endothelial cells results in physical disruption of capillaries, leading to the extravasation of blood and formation of petechial haemorrhage in a contusive animal experiment [19]. However, the mechanical factor that influences the molecular abnormality has not been identified. A further detailed investigation of the molecular mechanism of capillary fragmentation using an in vitro model is required.

Several previous studies have reported that mechanical stimuli regulate endothelial barrier function. A laminar fluid shear stress increases TEER transiently [20-22]; however, a disturbed flow decreases TEER [23]. Physiological cyclic stretch suppresses the decrease in TEER induced by thrombin, a barrier-disruptive chemical agonist, although a pathological cyclic stretch enhances the decrease [24,25]. Hydrostatic pressure below $16 \mathrm{mmHg}(\sim 2 \mathrm{kPa})$ continuously decreases the TEER in human Schlemm's canal and Madin-Darby canine kidney cell monolayers during $30 \mathrm{~min}$ [26]. We also demonstrated that impulsive pressure decreased the TEER in HUVEC, although the decrease in TEER by chemical stimuli such as EGTA was larger. In addition, a pressure pulse with larger amplitude decreased the TEER more if the duration was similar. For example, pressure pulse A of $352 \mathrm{kPa}$ decreased TEER more than pressure pulse $\mathrm{B}$ of $73 \mathrm{kPa}$, and pressure pulse $\mathrm{F}$ of $-91 \mathrm{kPa}$ decreased TEER more than pressure pulse $\mathrm{E}$ of $-67 \mathrm{kPa}$. A pressure pulse with shorter duration decreased TEER more if the amplitude was similar. For example, pressure pulse $\mathrm{B}$ of $27 \mathrm{~ms}$ decreased TEER more than pressure pulse $\mathrm{C}$ of $44 \mathrm{~ms}$, and pressure pulse D of $41 \mathrm{~ms}$ decreased TEER more than pressure pulse E of $104 \mathrm{~ms}$. A negative pressure decreased TEER more than did a positive pressure if the amplitude and duration were similar, such as pressure pulses $\mathrm{C}$ and $\mathrm{D}$. The increase in the peak amplitude, duration, or impulse of the applied positive pressure correlated strongly with the decrease in TEER after 15 min post-injury, with a correlation coefficient of $-0.75,0.54$, or -0.66 , respectively. The correlation coefficients for negative pressure were $0.32,-0.10$, and 0.27 , respectively. Gurdjian et al. reported that a shorter duration and higher amplitude correlated with the degree of cerebral concussion in the experimental concussion of dogs [4]. Hue et al. [27] reported that the blast overpressure acutely reduced the TEER in endothelial monolayers from a mouse brain microvascular cell line in a dose-dependent manner and that the decrease in TEER was strongly correlated with 

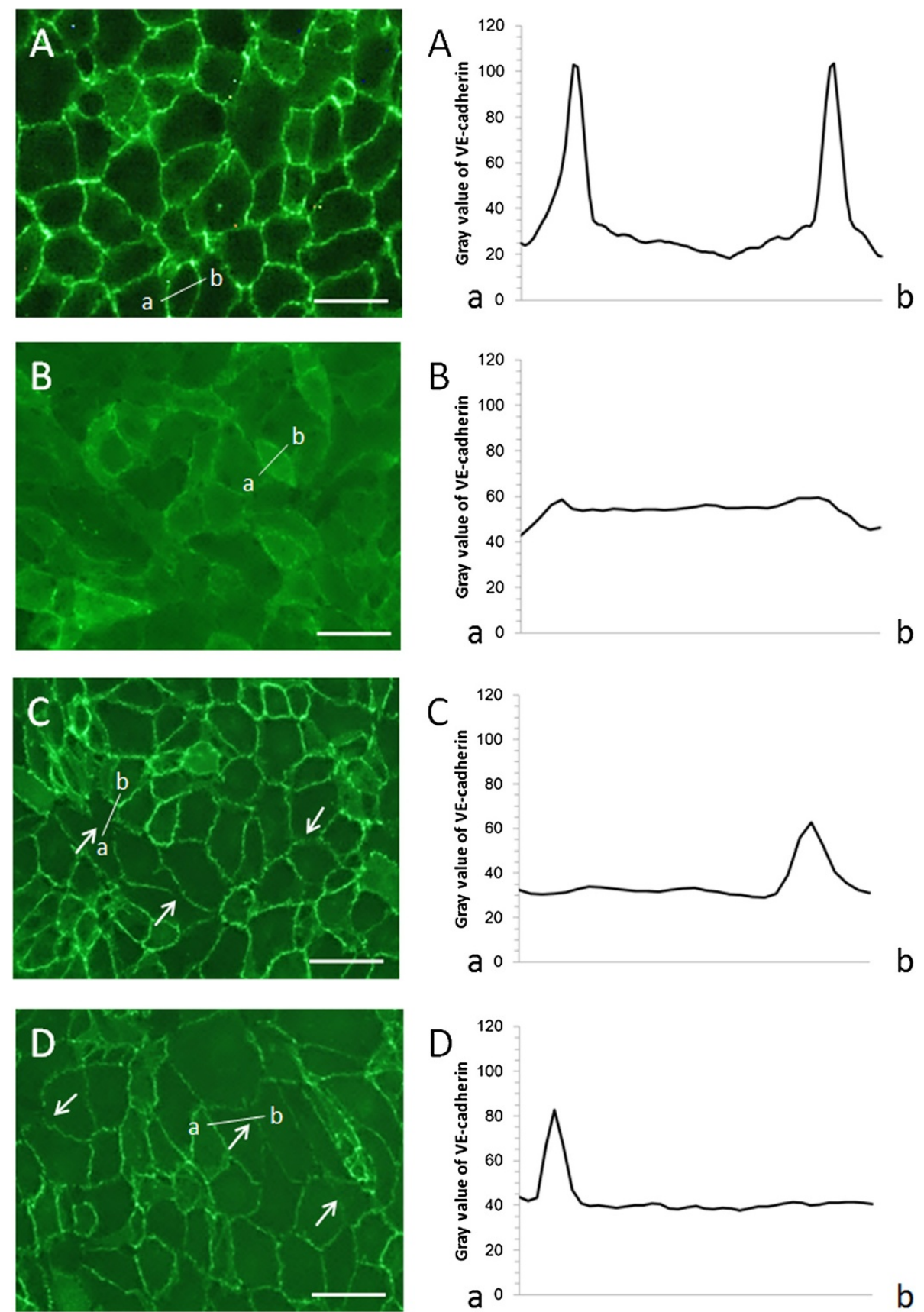

Figure 7 Fluorescent images and grey value profiles of VE-cadherin in endothelial cells after loading of impulsive pressure. VE-cadherin was observed in endothelial cells in a static culture (A), incubated with EGTA (B), and subjected to pressure pulses A (C) and F (D). Scale bar is $50 \mu \mathrm{m}$. Arrows indicate the loss of VE-cadherin in cell-cell contacts. The grey values of VE-cadherin were plotted along the cross-sectional surface of an endothelial cell along line $a-b$. The grey value of VE-cadherin increased in continuous cell-cell contacts in static culture (A), but remained relatively constant throughout the cells after EGTA incubation (B). The grey value did not change with the loss of VE-cadherin in cell-cell contacts after pressure loading (C and $\mathbf{D})$

the fluid peak overpressure or fluid impulse, as opposed to fluid duration. These reports corroborate our results, although insufficient combinations of peak amplitude and applied pressure durations have been used in this study. However, in this study, the TEER 
decreased when the pressure duration decreased against the increase in fluid duration. These differences in positive and negative correlation might be due to differences in impulsive pressure and blast overpressure. Moreover, we demonstrated that the decrease in TEER, i.e. the increase in endothelial permeability, is larger immediately and at $6 \mathrm{~h}$ after pressure loading compared to other measurement times. Cernak et al. reported that BBB permeability to Evans blue dye in the cortex and hippocampus of rats increased at $20 \mathrm{~min}$ and $4 \mathrm{~h}$ following moderate diffuse traumatic brain injury [28]. These results suggested that the amplitude and duration of the impulsive pressure generated by head impact and the elapsed time after head impact influence the degree of increase in endothelial permeability leading to the brain injury.

Endothelial cells, which cover the intravascular lumen in the monolayer, adhere to neighbouring endothelial cells; these endothelial cell-cell adhesions mainly consist of adherens junctions (AJs) and tight junctions (TJs). The endothelial permeability is regulated in part by the dynamic opening and closing of AJs, which are largely composed of VE-cadherin [17]. EGTA treatment caused TEER to drop to 30\% of the initial value associated with VE-cadherin localized throughout the cells, as shown in Figure 7B, in this study [16]. VE-cadherin monoclonal antibodies lead to an increase in vascular permeability in the heart and lungs of adult mice [29] and induce the redistribution of VE-cadherin from intercellular junctions to the cell membrane, as shown in Figure 7B, and block endothelial tube formation in cultured HUVEC [30]. In this study, the exposure to EGTA reduced TEER to $15 \%$ at $15 \mathrm{~min}$ associated with VE-cadherin localized throughout the cells. Therefore, this complete disruption of the integrity of endothelial cell-cell junctions could induce structural failure of the capillary, leading to bleeding such as cerebral contusion. On the other hand, the loading of impulsive pressure reduced TEER to $86-97 \%$ at $15 \mathrm{~min}$ associated with VE-cadherin localized intermittently along cell-cell contacts and partially in the cytoplasm. Therefore, this weak disruption of the integrity of endothelial cell-cell junctions could induce the opening of the BBB without structural failure of the capillary, leading to an increase in vascular permeability such as vasogenic brain edema.

On the other hand, TJs including occludin and claudins also regulate the paracellular permeability of endothelial cells [31]. The loss of occludin and zonula occludens-1 (ZO-1), which is a submembranous tight junction-associated protein, opens the BBB in the cerebral vascular endothelium of rats [32]. Blast overpressure reduces $\mathrm{ZO}-1$ in mouse brain microvascular endothelial cells associated with an increase in hydraulic conductivity and decrease in TEER [27]. However, HUVEC shows lower TEER and higher permeability to FITC-dextran than human brain microvascular endothelial cells (HBMEC) owing to a lack of occludin expression and lower expression of ZO-1 [33]. Therefore, further studies using HBMEC are required to elucidate the influence of impulsive pressure generated by head impact on BBB breakdown.

\section{Conclusions}

We developed a pressure loading device that can generate a positive pressure with amplitude of 53-1348 $\mathrm{kPa}$ and duration of 9-29.1 ms and a negative pressure with amplitude of $-52--93 \mathrm{kPa}$ and duration of $42.9-179.5 \mathrm{~ms}$ reproducibly by controlling the angle and weight of a pendulum. We used this device to demonstrate that impulsive pressure broke down the endothelial tube formation and decreased the TEER, which is associated with the 
change in VE-cadherin localization. In addition, the degree of decrease in TEER was larger when loading an impulsive negative pressure with larger amplitude and shorter duration. These results suggest that the transient changes in intracranial pressure during head impact would impair endothelial tube structures like capillaries and endothelial permeability by the disruption of the integrity of endothelial cell-cell junctions. The degree of increase in endothelial permeability depends on the amplitude, duration, and direction (compressive and tensile) of the impulsive pressure.

\section{Competing interests}

The authors declare that they have no competing interests.

\section{Authors' contributions}

HN designed the study and performed the statistical analysis. KI measured the device outputs and the TEER. SA observed the immunofluorescence staining. AK participated in the sequence alignment. SA conceived the study, participated in its design and coordination, and helped to draft the manuscript. All authors have read and approved the final manuscript.

\section{Acknowledgements}

This work was supported by Mitsui Sumitomo Insurance Welfare Foundation and by a Grant-in-Aid for Challenging Exploratory Research (20281248) from the Japan Society for the Promotion of Science.

\section{Author details}

${ }^{1}$ Graduate School of System Design, Tokyo Metropolitan University, Tokyo, Japan. ${ }^{2}$ Advanced Course of Mechanical and Computer Systems Engineering, Tokyo National College of Technology, Tokyo, Japan.

Received: 11 December 2013 Accepted: 4 April 2014

Published: 16 April 2014

\section{References}

1. Hardy WN, Khalil TB, King Al: Literature review of head injury biomechanics. Int J Impact Eng 1994, 15:561-586.

2. King Al: Fundamentals of impact biomechanics: part I-biomechanics of the head, neck, and thorax. Annu Rev Biomed Eng 2000, 2:55-81.

3. Lindgren S, Rinder L: Experimental studies in head injury. II. Pressure propagation in "percussion concussion". Biophysik 1966, 3:174-180.

4. Gurdjian ES, Lissner HR, Webster JE, Latimer FR, Haddad BF: Studies on experimental concussion: relation of physiologic effect to time duration of intracranial pressure increase at impact. Neurology 1954, 4:674-681.

5. Nahum A, Smith R, Ward C: Intracranial pressure dynamics during head impact. In Proceedings of 21st Stapp Car Crash Conference: 19-21 October 1977. New Orleans, Louisiana: Society of Automotive Engineers; 1977:337-366.

6. Trosseille X, Tarriere C, Lavaste F, Guillon F, Domont A: Development of a F.E.M. of the human head according to a specific test protocol. In Proceedings of 36th Stapp Car Crash Conference: 2-4 November 1992. Seattle: Society of Automotive Engineers; 1992:235-253.

7. Hardy WN, Mason MJ, Foster CD, Shah CS, Kopacz JM, Yang KH, King Al, Bishop J, Bey M, Anderst W, Tashman S: A study of the response of the human cadaver head to impact. Stapp Car Crash J 2007, 51:17-80.

8. Zhang Y, Aomura S, Nakadate H, Fujiwara S: Study of the mechanism of cerebral contusion based on the real-world brain injury accidents. Journal of Biomechanical Science and Engineering 2011, 6:191-202.

9. Morrison B 3rd, Elkin BS, Dollé JP, Yarmush ML: In vitro models of traumatic brain injury. Annu Rev Biomed Eng 2011, 13:91-126.

10. Shepard SR, Ghajar JB, Giannuzzi R, Kupferman S, Hariri RJ: Fluid percussion barotrauma chamber: a new in vitro model for traumatic brain injury. J Surg Res 1991, 51:417-424.

11. Orfeo T, Doherty JM, Adey G, Penar PL, Shatos MA: Sublethal percussion trauma in vitro causes a persisting derangement in the nonthrombogenic properties of brain endothelial cells. J Trauma 1994, 37:347-357.

12. Gourin CG, Shackford SR: Production of tumor necrosis factor-alpha and interleukin-1beta by human cerebral microvascular endothelium after percussive trauma. J Trauma 1997, 42:1101-1107.

13. Gourin CG, Shackford SR: Influence of percussion trauma on expression of intercellular adhesion molecule-1 (ICAM-1) by human cerebral microvascular endothelium. J Trauma 1996, 41:129-135.

14. DeWitt DS, Prough DS: Traumatic cerebral vascular injury: the effects of concussive brain injury on the cerebral vasculature. J Neurotrauma 2003, 20:795-825.

15. Nakadate H, Akanuma S, Aomura S, Kakuta A: Impact pressure increases permeability of cultured human endothelial cells. In Proceedings of ASME 2012 Summer Bioengineering Conference: 20-23 June 2012. Fajardo, Puerto Rico: American society of Mechanical Engineers; 2012. SBC2012-80117.

16. Rothen-Rutishauser B, Riesen FK, Braun A, Günthert M, Wunderli-Allenspach H: Dynamics of tight and adherens junctions under EGTA treatment. J Membr Biol 2002, 188:151-162.

17. Dejana E, Orsenigo F, Lampugnani MG: The role of adherens junctions and VE-cadherin in the control of vascular permeability. J Cell Sci 2008, 121:2115-2122.

18. Kurland D, Hong C, Aarabi B, Gerzanich V, Simard JM: Hemorrhagic progression of a contusion after traumatic brain injury: a review. J Neurotrauma 2012, 29:19-31. 
19. Simard JM, Kilbourne M, Tsymbalyuk O, Tosun C, Caridi J, Ivanova S, Keledjian K, Bochicchio G, Gerzanich V: Key role of sulfonylurea receptor 1 in progressive secondary hemorrhage after brain contusion. J Neurotrauma 2009, 26:2257-2267.

20. Seebach J, Dieterich P, Luo F, Schillers H, Vestweber D, Oberleithner H, Galla HJ, Schnittler HJ: Endothelial barrier function under laminar fluid shear stress. Lab Invest 2000, 80:1819-1831.

21. Shikata Y, Rios A, Kawkitinarong K, DePaola N, Garcia JG, Birukov KG: Differential effects of shear stress and cyclic stretch on focal adhesion remodeling, site-specific FAK phosphorylation, and small GTPases in human lung endothelial cells. Exp Cell Res 2005, 304:40-49.

22. Breslin JW, Kurtz KM: Lymphatic endothelial cells adapt their barrier function in response to changes in shear stress. Lymphat Res Biol 2009, 7:229-237.

23. Phelps JE, DePaola N: Spatial variations in endothelial barrier function in disturbed flows in vitro. Am J Physiol Heart Circ Physiol 2000, 278:H469-H476.

24. Birukov KG, Jacobson JR, Flores AA, Ye SQ, Birukova AA, Verin AD, Garcia JG: Magnitude-dependent regulation of pulmonary endothelial cell barrier function by cyclic stretch. Am J Physiol Lung Cell Mol Physiol 2003, 285:L785-L797.

25. Birukova AA, Rios A, Birukov KG: Long-term cyclic stretch controls pulmonary endothelial permeability at translational and post-translational levels. Exp Cell Res 2008, 314:3466-3477.

26. Burke AG, Zhou W, O'Brien ET, Roberts BC, Stamer WD: Effect of hydrostatic pressure gradients and Na2EDTA on permeability of human Schlemm's canal cell monolayers. Curr Eye Res 2004, 28:391-398.

27. Hue CD, Cao S, Haider SF, Vo KV, Effgen GB, Vogel E 3rd, Panzer MB, Bass CR, Meaney DF, Morrison B 3rd: Blood-brain barrier dysfunction after primary blast injury in vitro. J Neurotrauma 2013, 30:1652-1663.

28. Cernak I, Vink R, Zapple DN, Cruz MI, Ahmed F, Chang T, Fricke ST, Faden Al: The pathobiology of moderate diffuse traumatic brain injury as identified using a new experimental model of injury in rats. Neurobiol Dis 2004, 17:29-43.

29. Corada M, Mariotti M, Thurston G, Smith K, Kunkel R, Brockhaus M, Lampugnani MG, Martin-Padura I, Stoppacciaro A, Ruco L, McDonald DM, Ward PA, Dejana E: Vascular endothelial-cadherin is an important determinant of microvascular integrity in vivo. Proc Natl Acad Sci USA 1999, 96:9815-9820.

30. Corada M, Liao F, Lindgren M, Lampugnani MG, Breviario F, Frank R, Muller WA, Hicklin DJ, Bohlen P, Dejana E: Monoclonal antibodies directed to different regions of vascular endothelial cadherin extracellular domain affect adhesion and clustering of the protein and modulate endothelial permeability. Blood 2001, 97:1679-1684.

31. Wolburg H, Lippoldt A: Tight junctions of the blood-brain barrier: development, composition and regulation. Vascul Pharmacol 2002, 38:323-337.

32. Bolton SJ, Anthony DC, Perry VH: Loss of the tight junction proteins occludin and zonula occludens- 1 from cerebral vascular endothelium during neutrophil-induced blood-brain barrier breakdown in vivo. Neuroscience 1998, 86:1245-1257.

33. Man S, Ubogu EE, Williams KA, Tucky B, Callahan MK, Ransohoff RM: Human brain microvascular endothelial cells and umbilical vein endothelial cells differentially facilitate leukocyte recruitment and utilize chemokines for T cell migration. Clin Dev Immunol 2008, 2008:384982.

doi:10.1186/1475-925X-13-44

Cite this article as: Nakadate et al:: Effect of amplitude and duration of impulsive pressure on endothelial permeability in in vitro fluid percussion trauma. BioMedical Engineering OnLine 2014 13:44.

\section{Submit your next manuscript to BioMed Central and take full advantage of:}

- Convenient online submission

- Thorough peer review

- No space constraints or color figure charges

- Immediate publication on acceptance

- Inclusion in PubMed, CAS, Scopus and Google Scholar

- Research which is freely available for redistribution

Submit your manuscript at www.biomedcentral.com/submit 